\title{
Exploring the State of Diversity as an Opportunity to Strengthen Student Tutoring in Institutions of Higher Learning: The Case of Two Higher Education Institutions in South Africa
}

\author{
Prof. S. M Kang'ethe \\ University of Fort Hare, Department of Social Work and Social Development \\ Box X1314, ALICE. 5700, South Africa \\ Email: skangethe@ufh.ac.za \\ Dr Patricia Muhuro \\ Senior Consultant, Teaching and Learning Centre, University of Fort Hare \\ Email: PMuhuro@ufh.ac.za
}

Doi:10.5901/mjss.2014.v5n15p241

\begin{abstract}
While student diversity is a common phenomenon in contemporary higher education, there seems to be no consensus among scholars as to whether diversity is valuable or worthless to student learning. Using tutorial programme as one example of academic support strategy where student diversity prominently features, the study explored the importance of diversity in enhancing student learning in higher education. The study employed a case study of two universities in South Africa, one being a traditional university while the other was a comprehensive university. Participants for the study consisted of 24 purposively selected trained tutors who took part in focus group discussions and 6 tutor trainers who responded to in-depth interviews. Document analysis was used to corroborate findings from the focus group discussions and interviews. The study came with the following findings presented by diversity: It allowed for the development of active thinking skills among the students; made tutorials ineffective as different students wanted their cultural diversity to be addressed; made age to negatively undermine the role of the tutors, and also affected the attendance of the tutees; made diverse cultures influence student learning. The researchers recommend diverse classroom diversity awareness sessions.
\end{abstract}

Keywords: Cross age tutoring, culture, pair-shared tutoring, Diversity, tutoring, student support, classroom diversity, language, diversity awareness, orientation programme

\section{Background and Introduction}

In simple and a layman's understandable language, diversity refers to variety (Kirk \& Durant, 2009). In the same vein, Zastrow and Kirst-Ashman (2013: 10) defines diversity as a range of differences among groups of people including those related to age, class, colour, culture, disability, gender, gender identity and expression, immigration status, political ideology, race, religion, sex and sex orientation. According to the United Nations Educational Scientific and Cultural Organisation (UNESCO) (1998), all people irrespective of backgrounds should be given an opportunity to participate in higher education. This is called "open access". This open access has resulted in student diversity, a phenomenon of interest to higher education providers and researchers. Diversity is believed to present different challenges and opportunities to student learning (Du Plessis \& Bisschoff, 2007; Meier \& Hartell, 2009).

Scholars who opt for increased student diversity contend that it is beneficial to student learning and embraces democratic outcomes (Gurin et al., 2002; Brussow \& Wilkinson, 2010). Such scholars are of the view that most students may not be fully exposed to various forms of diversity prior to enrolling in higher education. Therefore, higher education provides an opportunity for students to move out of their comfort zones and experiment with new ideas, environments and new people. However, this may not be easy to achieve because it requires a paradigm shift of the mind and high levels of tolerance to divergent views and environment one is accustomed to. For instance, Gurin, Dye, Hurtado, \& Gurin (2002) identified three related forms of diversity namely, structural diversity, classroom diversity, and informal interactional diversity. Structural diversity is a direct result of formal open admission policies leading to proportional representation of people with varied characteristics in the same institutional setting. Structural diversity gives way to informal interactional diversity where students and staff of different groups interact with one another informally and in 
adhoc fashion. Classroom diversity consists of structured interactions among diverse people and includes direct teaching of students about diversity, infusing diversity illustrations in disciplinary content, as well as exposing students authentic learning experiences with diverse people on campus.

Classroom diversity is the main focus for this study. This is because it can enhance active engagement with diversity content, resulting in learning outcomes such as motivation, tolerance, intellectual engagement, and active thinking (Gurin et al, 2002; Shaw, 2009;Brussow \& Wilkinson, 2010). Also, classroom diversity allows students to appreciate democratic outcomes such as citizenship, racial and cultural tolerance, and compatibility among different groups (Gurin et al, 2002:334). Classroom diversities manifest in tutorial groups where students have to learn from each other despite their differences. Tutorials are an academic student support strategy where one student takes the responsibility of academically supporting fellow students in their learning (Topping, 1996). It is however important to understand the means and ways in which these differences are handled in order to foster effective learning.

A contrary view holds that diversity brings about learning complexities which inhibit learning (Du Plessis \& Bischoff, 2007). Such complexities may include prejudice, different learning abilities, low motivation and self esteem challenges, loss of confidence and negative dispositions. Such complexities could emanate from political, socio-cultural and economic socialisations. For instance remarkable age and ability differences between the tutor and tutees may cause the tutor to become authoritarian and thus inhibit tutee effective confidence, trust and openness (De Smet et al. 2008). On another angle, tutees and lecturers may have too many contradictory expectations which the tutor may be unable to fulfill because of diverse needs ( Roscoe \& Chi, 2008). Actually, differing expectations between students and the tutor on how tutorials should be conducted can cause frustrations on both the tutor and the students (Shaw, 2010). Also, due to cultural reasons, students may experience gender prejudice in teaching resources and also in teaching methods adopted by tutors (Chisholm, 2004). Apart from gender differences, language diversity may make it difficult for tutors and tutees to effectively communicate, especially if they are from different language backgrounds (Carella, 2010). Even though most higher education institutions use English as the main language of learning and teaching, most students particularly those in their first year of study exhibit low level English language mastery (Alsup, 2008; Du Plessis \& Bischoff, 2012). Some scholars have advocated for the infusion of these language skills in disciplinary content as the most effective way of developing the required language of learning skills in higher education (Wingate, Andon \& Cogo , 2011).

It is also important that institutions of higher learning have well developed structures to locate and identify such students' diverse needs so as to support them. McInnis (2001) identified various strategies that are believed to improve student diversity in higher education, one of which is peer academic and social support. The same approach is also supported by many other scholars. In this approach, students may be deliberately assigned to subgroups consisting of diverse individuals. However, simply grouping together diverse students does not guarantee effective learning, but may rather perpetuate prejudice among individuals. Rather, the curriculum for tutorials should allow for systematic learning for students, including reinforcing of learning material to improve understanding (Topping, 1996; Adams, 2007). Such students may require some individualized attention to deal with academic, socio-emotional and economic issues affecting their learning and success. Student centred pedagogies make the student to feel valued (Cuseo, 2002). Support for such students must emanate from institutional visions and missions which emphasise on tolerance, inclusivity and democracy, as well as practices that make all students feel that they are valuable members of the university community (Thomas, 2002; Tinto \& Pusser, 2006). This can be achieved through pedagogical practices that emphasize high expectations, continuous encouragement, and not being judgmental of the student characteristics (Topping, 1996) and peer support (Mastopieri, Margo, Shruggs, Thomas, \& Berkely, Sheri, 2007). Also, a tutor must have maturity and professional qualities to rekindle and motivate those being tutored. These qualities are believed to develop tutee self-esteem, locus of control, self-regulation and independence, all of which are essential for learning (Gisbert \& Font, 2008). This supportive environment is however not always visible in most institutions of higher learning (Tinto \& Pusser, 2006). In the case of South African higher education, Du Plessis (2012) found that most of the tutors, though being well performing students, lacked the optimal qualities and personalities which promote students' learning.

\section{Statement of the Problem}

Succinctly, the realization of the multi-facetedness embedded in the continuum of any educational setting remains one of the most critical aspects of understanding learning. To this end, it is important to consider the aspect of student diversity as a pillar to explore their learning prowess. This is because diversity is believed to present different challenges and opportunities that can affect learning (Du Plessis \& Bissschoff, 2007; Brussow \& Wilkinson, 2010; Meier \& Hartell, 2009). The benefits of diversity lie in the development of student's skills in appreciating divergent views (Pascarella \& Terrenzini, 1991, 2005; Gurin et al., 2002;Shaw, 2009). Furthermore, diversity can also be a source of cultural conflict (Reeves \& 
Dryden, 2008). Therefore, conducting a research on the dynamism of diversity among the learners, whether empirical or otherwise, is topical, critical and scientifically welcomed.

\subsection{Methodology}

In order to explore tutors views and experiences on diversity, a descriptive qualitative method was adopted. According to Silverman (2011), qualitative research regards social reality as constantly shifting based on individuals' creation and deductive interpretation of the phenomenon. Hence, as alluded by Cresswell (2007) that qualitative researchers value participants' verbal and non verbal perspectives on experiences, values and assumptions on issues, the current study focused on tutors and tutor trainers' perspectives on how diversity in tutoring can enhance student learning. Qualitative researchers also value conducting research in natural settings, hence all the data was collected in the universities where the participants conduct daily business, with focus groups conducted in a usual training room while interviews were done in the tutor trainers' offices. The researchers were mainly interested in how tutors and tutor trainers make sense of the phenomenon of diversity in relation to promoting students' learning .

\subsection{Research Design}

The study adopted a case study design of one comprehensive university and one traditional university in South Africa. These are typical examples of universities with diverse students and staff complements. Therefore, data from these institutions provided a clearer picture of the diversity phenomenon. Yin (2009:2) asserts that a case study design is ideal when considering typical "contemporary phenomenon within a real life context" and advises that "multiple sources of evidence should be used so that the data can converge in a triangulation fashion".

\subsection{Research Methods}

In line with Yin's (2009) idea of involving multiple sources of evidence, this study employed 4 focus groups discussions on 24 tutors and indepth interviews on 6 tutor trainers. The same interview guide was used. Focus groups were chosen because they provide a quick method to collect diverse views from many tutors in minimal time possible (Maree, 2007; Krueger \& Casey, 2009). On the other hand, the indepth interviews curbed the weaknesses of focus groups in that each participant had an opportunity to express themselves without fear of intimidation. Each focus group consisted of about six people and lasted for approximately one hour. Kruger and Casey (2009) contend that the interactive and social nature of focus groups allows diverse expressions (verbal or non verbal) from the participants and provide evidence about similarities and differences in the participants' opinions of phenomenon. Face to face interviews were also conducted with the tutor trainers and each interview lasted about thirty minutes. Interviews were aimed at corroborating findings from the focus group discussions concerning tutors' appreciation of diversity and how this is translated in the classroom in supporting student learning.

All discussions were done in English because this is the official language of teaching and learning in the institutions that were part of the research domain. In order to ensure that the data was collected in natural settings, interviews were conducted in the offices of the respective trainers while the focus group discussions were conducted in the training rooms for tutors. Although some of the discussions were tape recorded, the researcher also jotted down notes to assist in identifying the different speakers.

\subsection{Sample Selection Criteria and Procedure}

The two universities were chosen conveniently because they provide typical cases of diversity in South African higher education. Traditional universities mainly offer professional academic programmes while comprehensive universities offer both vocational and professional academic programmes (DoE, 2005). Students from these two types of universities are diverse in terms of prior learning experiences, age, learning styles and strategies, gender, culture and language. All these diversities influence student learning.

This study's sampling frame composed of the lists of tutors and tutor trainers and the information was derived from the institutional databases. Purposive sampling procedures were used to decide on the 24 tutors and 6 staff members who participated in the study. According to Drew, Harman and Hopps (2008), purposive sampling is favoured because it allows the researcher to select the most appropriate participants to answer research questions of the study. Therefore, the tutors and the tutor trainers were the unit of analysis who had first hand experience in issues of student support and 
handling diversity. Tutors were all drawn from the science disciplines because statistics hold that there is a high shortage of professionals in science disciplines in Southern Africa. Also, the selection criteria was at least one year experience as a professional tutor because it was assumed that professional training empower the tutors to understand the importance and strategies of handling student diversity in the classroom. Also, trained tutors are believed to use productive teaching strategies that enhance deep reasoning and thinking skills (Carella, 2010). The research participants were of diverse ages, cultural backgrounds and prior undergraduate learning. The staff were selected based on their involvement in the tutorial programmes either as co-coordinators or trainers.

\subsection{Ethical and legal considerations}

Permission to conduct this research was sought from institutional managers through the research ethics committees who provided an authorization letter. The letter allowed the researchers to access institutional documents, as well as carry out focus groups discussions and in-depth interviews with staff and tutors who were willing to participate. Also, in line with Bryman's (2012) emphasis on the need to ensure that the research participants are made aware of the purpose of the research, a written document outlining the purpose of the study was given to each participant. Each participant was also requested to sign an informed consent form as evidence of willingness to participate in the study. As part of the legal and ethical requirements, the researcher upheld the confidentiality of participants by using pseudonyms when presenting and reporting on the data (Bergman, 2008). They were not compelled to disclose information and had an option to withdraw from the study anytime they wished. All the information were tape recorded pending approval and consent of the respective respondents. The researcher took notes in instances where participants rejected to be voice recorded. Silverman (2011) highlights the need to provide information written in a language that the respondents can understand. The document explaining the purpose of the study and the questions were written in English since it is the official language used within the two universities. However the language used was very simple to allow all participants to understand the data sought for.

\subsection{Data analysis and interpretation}

The data for the study was analysed inductively. This means that emerging themes were derived from recurring patterns in the data, interim analysis were employed and the key information coded, identified and classified according to the main themes that emerged. In this regard, the themes were placed into appropriate categories, subcategories and meaning embedded in them sought out.

\subsection{Data Credibility and trustworthiness}

Bryman (2012) asserts that multiple perspectives on a phenomenon can increase validity or trustworthiness. Hence, multiple perspectives in data collection were used through triangulation of research instruments and data analysis. The data omitted in some of the research instruments was captured from the other quarters to enhance validity.

Trustworthiness is a way of ensuring accuracy of data in qualitative approaches. Trustworthiness has to deal with the way the researcher claims that the research is "worth paying attention to" or accurate (Leedy \& Ormroid, 2010). Authenticity of the data in the study was achieved through member checking. The transcribed data was sent to participants to edit, clarify, elaborate and at times remove their own words from the narratives if they were not comfortable with the recording. Also, all the interviews were tape-recorded so as to capture full details of the conversations. In instances where the respondents were uncomfortable to be recorded, field notes were used (Bryman, 2012). In order to ensure credibility of the findings, member checking was employed.

\subsection{Limitations of the Study}

Student diversity is both a complex and a contested issue (Fraser and Killem, 2005). Although information on diversity and ways to handle it exists, these strategies may be context specific and may not be generalized across higher education. The data was collected in 2012 and by now (2014) institutional policies and practices on handling diversity may have changed. However, most of the findings and suggestions are still relevant to those institutions that are still battling with finding best practice in supporting diverse students. The research did not involve lecturers who are also key stakeholders in the success of support initiatives. Their opinions and experiences could have hopefully shed more light on the phenomenon and augment the study results. 
Even though the researcher initially intended to carry out more focus group discussions, time constraints inhibited both the researcher and the tutors to meet in the scheduled times. Another possible contribution to the constraint was the timing of data collection because data was collected towards the end of the year examinations.

\title{
3. Findings
}

\subsection{Diversity allowed for development of active thinking skills}

The research responses indicated that there were some benefits of diversity in the classroom. To this end, tutors were of the view that they got new perspectives about society as well as how different people interpret issues.

\begin{abstract}
Although we have our own differences in the tutorials, we have managed to get different perspectives about how different people make sense of issues. It has prompted us to also think carefully about how our communities differ from others (FGD2,2)

As the students discuss issues with others, they get to correct their own mistakes and also develop new knowledge ( FGD3, 1)
\end{abstract} tutorials

However, the findings also show that there were challenges associated with having diverse students in the

\subsection{Diversity made tutorials ineffective}

Responses from the FGD with tutors indicated that student diversity made the programme ineffective because the tutors were confronted by various kinds of problems that they did not have immediate answers for. This was evidenced by the following sentiments:

There are too many challenges we face because sometimes students want their needs to be handled in their own perspective. This sometimes contradicts with how we have been trained. For example, students want to be spoonfed, yet they ought to be developing independent learning attributes. So they usually complain if they are not taught the way they think they should be taught (FGD1,2).

I have noticed that the mature students who have been out of school for sometimes struggle to recall concepts. So I usually ask them to work in pairs so as to share ideas. But this pairing is not always successful because of too much dependence (FFG3,4)

Findings from the tutors unexpectedly revealed that the phenomenon of diversity was not positively working for the success of the tutorial programme. Also, the response above shows that an attempt to infuse peer learning through paired support can lead to high dependence due to ability differences and student learning styles. The scenario above could be a direct result of lack of responsibility or poor peer- learning guidance on the part of the peer leaders. It is also possible that the tutors did not have requisite skills to adequately handle the tutees.

\subsection{Age negatively undermined the role of tutors}

Findings on diversity indicated that some learners who were older undermined the tutors who were younger than them. This phenomenon posed learning difficulties because the intake of learners did not discriminate age. The following sentiment bears witness to the finding:

The challenge I am experiencing is that some of the students are not accepting advice because I am younger than them. I find myself being belittled by the people I am supposed to assist and this is frustrating (FFG, 2, 1).

The response above confirms the assertion that shows that open access policies have resulted in much older students entering higher education . Although peer support is a tested strategy for enhancing learning, the practice of having tutees who are older than the tutor creates problems. The scenario mentioned in the findings above where older students were undermining the younger tutors may be implying that the tutees had not been fully oriented in the issue of diversity. Perhaps the scenario above points to the need of ensuring that tutors be of the same age or older as proposed by proponents if cross age tutoring was to bear great dividends. Also, the above may be pointing out to possible limited opportunities to openly discuss diversity issues in the classroom so that all students appreciate its benefit for their own learning. 


\subsection{Diverse Cultures influence student learning}

Findings on diversity brought to the fore the need to respect different aspects of different cultures if learning was to be smooth and accommodate various cadres of personalities. For example, it became clear that the elderly students in tutorials were not embracing to be tutored by tutors who could have been of the age of their children. This is because according to the elderly students, younger individuals or children do not give the elders instructions, but rather take advice and orders from the elders. This is possibly due to the strong cultural values in African settings.

\section{"It is important that the education system respect our cultures. We conceptualize things through our cultural lenses" "Seeking advice from a stranger is not accommodated by my culture"}

The challenge that culture as an integral aspect of diversity presented posed some challenges as the students could not freely seek advice from their younger colleagues and yet the universities did not have any special arrangement to accommodate the various aspects of culture like having the lecturers or tutors be of specific age for some classes with elderly students.

\subsection{The language of the tutors influence the class attendance}

Findings on language of instruction as an integral component of culture was found to influence students attendance to tutorials and therefore learning. This is supported by the following sentiments from the students:

"Some of the tutors speak in their mother tongue and freely communicate with those from the same language. I however feel out of place because I do not make sense of the local language. I think tutors should all teach us in English "I only attend the tutorials managed by a tutor who I can ask questions in my own language. I feel free and at liberty when I ask questions in my language, Isixhosa"

Although English is the official language of communication in universities, there were mixed views among students concerning its use in tutorial sessions. Regrettably, and to the expense of language development, the use of English language during tutorials was not appreciated or embraced by all the freshmen as some had low mastery of it. On one hand, some first year students felt the urge to attend tutorials managed by tutors who were able to accommodate them through explaining difficult concepts in their language. On the other hand, however, the existence of diverse languages in the same tutorial groups did not make this approach a viable solution to students learning needs. This aspect of diversity, therefore, remained a challenge to learning in higher education and requires further exploration.

\section{Discussion of the Findings}

The finding from the study shows several benefits of diversity in the classroom. Most importantly, the diversity of varied academic ability was beneficial in instances where students were active in the learning process and learnt from each other. In fact many scholars argue that active participation of diverse students strengthens learning through tutorials because of the opportunity to seek clarification, developing skills in critiquing and other practical academic capabilities in small groups (Topping, 1996; Meier \& Hartell, 2009). Alsup (2008) also found that coaching provided by tutors allowed students of different abilities to benefit from the discussions which elicited different viewpoints that each individual student could not think of on their own. This implies that student diversity in the tutorial learning enhances active thinking. However, the study also noted some challenges in relation to differing age of students. Due to open access policies which allow everyone to participate in higher education irrespective of background, some of the tutors were younger and were undermined by their tutees. In this instance, this aspect of diversity presented challenges that needed to be addressed since all the students' needs needed to be addressed irrespective of age (Lemens \& Maitlad, 2008).

In tutoring principles, a tutor can be any person in possession of more knowledge and experience and older than the tutees in the case of cross age tutoring, or of the same age and of the same ability in the case of same age peer tutoring (Topping, 1996). However, the finding above deviates from past findings where elderly tutors were the ones well known to be authoritarian and inhibiting tutee confidence and active learning (De Smet et al., 2008). Perhaps trying to match the elderly learners with an apparently elderly tutor could help improve the situation. It appears that same age and different ability peer tutoring technique was not equally successful as paired-shared learning led to some students being too dependent on others for their learning. Reciprocal peer tutoring could be another alternative to ensure that the age gap and the ability differences are neutralized as each of the students takes the role of a tutor alternatively and at turns. 
However, reciprocal peer tutoring appears to mitigate the power dynamics related to cross age tutoring.

Possibly, the age differences elucidate strong influence of culture on students' perceptions and expectations of the learning dynamics in the tutorial sessions. Using cultural lenses and perspectives, younger people ought to get instructions from their elders and not vice versa. This means that most of the tutees found it awkward to be receiving instructions from people who were the age of their children and maybe siblings. It is possible that such tutees also found it difficult to ask questions for clarification, not only to the tutees, but also to the younger lecturers. This finding agrees with observations that cultural beliefs can be an impediment to learning if students are not well orientated on diversity issues (Kirk \& Durant, 2009). Perhaps it is critical that diversity issues be constantly discussed especially in the classroom for all students to appreciate various aspects of it. The challenge sometimes is that diversity issues may only be highlighted during student orientation, but there are minimal follow up seminars to address them. It is critical that various aspects of diversity that could affect any kind of learning are explicated in the classroom environment. The instructors should be challenged to explore all such factors.

The findings also showed that multi-language settings presented challenges for some students. The findings indicated that those students who had low mastery of the English language were uncomfortable with a tutor or tutors who was/were not speaking their own language. On one hand, the scenario supports the view that high school curriculum is doing little to prepare students for higher education demands. To this end, Sondlo, \& Subotsky (2010) contend that the secondary education has not fully prepared the new entrants to higher education. Given that English language is one of the core subjects that a student has to pass before being admitted to higher education, such students reservations on tutors using English point to serious prior education learning gaps, especially in learning English. However, intentionally designed classroom activities embedded in the curriculum allowing students to constantly practice using English in formal and informal way may reduce the fear and lack of confidence that most first year students have. To this end also, Wingate, Andon, \& Cogo ( 2011) recommend that the infusion of English as well as reading and writing in the teaching of each and every course can help diverse students to finally develop a better understanding of the language. This approach would be particularly benefitial to those who have diverse mastery of English.

\section{Conclusions and Recommendations}

Institutions of higher learning need to understand the potential benefits and hurdles that diversity can pose and therefore put in interventions that will arrest the challenges. This study explored student classroom diversity in two institutions of higher learning using a case study approach. Participants comprised of tutors and their trainers. The current study found that diversity relating to age, culture and language of learning were most influential to student learning than other forms of diversity. Benefits of diversity manifested through a supportive learning environment for students of varied learning abilities through coaching and collaborative learning in tutorials. Class discussions also elicited divergent views and thus developing skills in tolerance and teamwork and active thinking. However, some challenges were also noted in handling diversity related to cultural aspects.

The study recommends the need to carry out diverse diversity awareness sessions in the course content, institutional visions and missions, and in the academic and social programmes.

\section{References}

Alsup, J. (2008). Tutoring is real. The benefots of the peer tutor experience for future English educators. Pedagogy , 327-347.

Babbie, E. (2007). The Practice of Social Research (11th Edition ed.). Belmont: Thompson Wadsworth.

Bass, G. (2007). An Investigation of the Perceptions of Learners and staff in respect of the Dental Technology Extended First Year Programme. Masters Thesis. University of Kwazulu Natal. University of Kwazulu Natal. Unpublished.

Bergman, M. (2008). Advances in Mixed Methods Research: Theories and Application. London : SAGE.

Bless, C. Higson-Smith, C. \& Kagee, A. . (2007). Fundamentals of Social Research (4th Edition ed.). Claremount: Juta.: An African perspective.

Brown, M. (2000). Improving students writting proficiency and attitude towards peer revision through peer collaboration: Case study of student reviewers. University of West indies, School of Education Department of Educational Studies . Mona: Wildcat.

Brussow, S.M \& Wilkinson, A.C. (2010). A Pathway to better engaged learning. South African Journal on Higher Education, 374-391.

Bryman, A. (2012) . Social Research Methods (4th ed.). Oxford. Open University Press.

Campbell, L. Campbell, B. \& Dickinsion, D. (2003). Teaching and Learning through multiple intelligenges (3rd ed). Boston: Pearson Education.

Carella, A. (2010). Identifying college student success. The role of first year success courses and peer mentoring. Unpublished dissertation. University of Arizona. Tuckson: Wild Cat.

Chisholm, L. (2004). Gender Equity in South Africa. Cape Town : Oxford University Press 
Council on Higher Education (CHE) (2009). Higher Education Monitor: The state of higher education report. Pretoria: CHE.

Council on Higher Education (CHE) (2010). Access and Throughput in South African Higher Education: Three Case Studies. Higher Education Monitor No. 9, March. Pretoria: CHE.

Cuseo, J. B. (2002). Igniting student involvement, peer interaction, and teamwork: A taxonomy of specific cooperative learning structures and collaborative learning strategies. Stillwater, OK: New Forums Press.

Davies, B. (1993, 10 01). Diversity and Complexity in te classroom cpmsoderation for race, ethinicity and gender. Retrieved 0108,2012 , from http:www.cirtl.netlnodesl54499

Drew, C. J., Hardman, M. L. and Hosp, J. L. (2008). Designing and Conducting Research in Education. California: Thousand Oaks.

Du Plessis, P. \& Bischoff, T. (2007). Diversity and Complexity in the classroom; valuing racial and

cultural diveristy. Educational Research and Review, 2 (9), 245-254.

Du Plessis, L. G. (2012). Academic Preparedness of students: An exploration study. Journal of Transdisciplinery Research in Southern Africa , 8 (1), 81-94.

Fraser, F., \& Killem, M. (2005). Perceptions of some students and lecturers of some factors affecting academic perfromance in two South African universities. Perspectives in Education , 23 (5), 25-40.

Gisbert , D.D. \& Font, C.M. (2008). The impact of peer tutoring on the improvement of linguistic comptence self concept as a writer and pedagogical satisfaction. School of psychology international , 29 (4), 481-499.

Gurin, P., Dye, E.,Hurtado, S., \& Gurin, G. (2002). Diversity in higher education: Theory and impact on educational Outcomes. Harvard Educational review, 72 (3), 330-368.

Kirk, D. \& Durant, D. (2009). Crossing the line: Framing Apporpriate Responses in the Diversity Classroom. Journal of Management Education, 823.

Khan, J. A. (2011). Research Methodology. New Dehli: APH Pubilshing.

Krueger, R. A.,\& Casey, M.A. (2009). Focus Groups: A Practical guide for Applied Research (4th Edition ed.). Thousand Oaks Calif: SAGE.

Leedy, P. \& Ormrod, J. (2010). Practical Research: planning and design (10th ed.). Thousand Oaks:New Jersey: SAGE Publications

Lemens, I \& Maitlad, E. (2008). Meeting social and emotional needs of students through peer tutoring . Acta Academia , 43 (4), $127-151$.

Lea, M. R.\& Street, B.V. (2001). The Acadmeic Literacies Model : Theory and Applications, Theory into Practice. Studies in Higher Education .45(4), 368-377.

Letseka, M., \& Maile, S. (2008). High Student Dropout a threat tho South Africa's future. Cape Town: Human Sciences Research Council.

McInnis, C. (2001). Signs of Disengament? The changing undergraduate experience in Austrialian Universities. Melbourne, Australia: http://www.sshe.unmelb.udu.au/downloads/inaugLec23801.pdf_25July 2002.

Madni, A. (2008). Do the Perceptions of the usefulness of academic support services influence help seeking attitudes and behaviours. Doctoral thesis , University of Southern Califonia, Rossier School of Education, Califonia.

Maree, K. (2007). First Steps in Research (1st Edition ed.). Pretoria: Van Schaik Publishers.

Mastopieri, Margo, Shruggs, Thomas, \& Berkely, Sheri. (2007). Peers helping peers. Educational Leadership , 64 (5), $54-58$.

Meier, C. \&. Hartell, P. (2009). Handling cultural diversity in education in South Africa. South Africa Educational Journal , 6 (2), $180-192$.

Pascarella,E.,Terrenzini, P. (2005). How College Affects Students: A Third Decade of Research (Vol. II). San Francisco: Jssey-Bass Higher \& Adult Education.

Robbinson,G.R Schoefield K.W. \& Steers -Wentzell,K.L. (2005). Peer and cross age tutoring in Maths. Outcomes and their design implications. Educational Psychology Review, 17 (4), 327-364.

Roscoe, R. D., \& Chi, HHM. (2008). Understanding tutor learning, knowledge building and knowledge telling. Review of Educational Research, 77, 534-574

Roberts, D. (2005). Learner support in South African Distance Education. A case for action. UNISA Press. 1-14..

Silverman, D. (2011). Qualitative Research: Issue of Theory Methods and Practice (3rd ed.). London: SAGE.

Shaw, J. (2009). The diversity paradox. Journal of Further and Higher Education , 33 (4), 321-331.

Sondlo, M., \& Subotsky, G. (2010, August). The challenges facing the South African Secondary schooling system and their implications for Higher Education. DISA: Information Analysis Briefing .

Pusser, B., \&Tinto, V. (2006). Moving from theory to action. Building a Model for Institutional action. Enhancing Holistic Student Development and Success. National Postsecondary Education Co-operative .

Tinto, V. (2013, August 23). Theoretical underpinnings and research. Cape Town, Western Cape, South Africa.

Thomas, L. (2002). Student retention in higher education: the role of institutional habitus. Journal of Education Policy , 17 (4), $423-442$.

Topping, K. (1996). Reaching where adults can not: Peer education and peer counselling. Educational Psychology in Practice , 11 (1996), 23-29.

UNESCO. (1998). World Declaration on higher education for the 21st century: Vision and Action. Paris: United Nations Educational, Scientific and Cultural Organisation.

Weissman, J \& Bonning , K.J. (2003). Five features of effective courses. Journal of general education, 52 (3), 150-174.

Wingate, , U., Andon, N., \& Cogo A. (2011). Emebdded academic writting instruction into subject teaching: A case study. Active Learning in Higher Education , 12 (1), 69-81.

Yin, R. (2009). Case Study Research. Design and Methods (4th Ed). London: SAGE.

Zastrow, C.,\& Kirst-Ashman, K.K. (2013). Understanding Human Behaviour and the Social Environment (5th ed.). Belmont, CA: Thompson learning. 